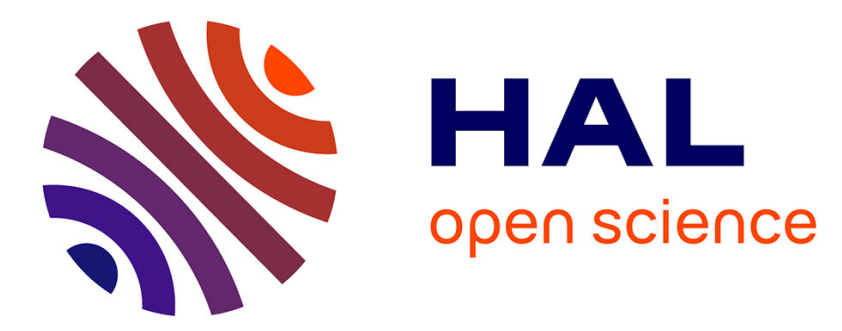

\title{
Refinement of Knowledge Sharing Platforms to Promote Effective Use: A Use Case
}

\author{
Carine Edith Touré, Christine Michel, Jean-Charles Marty
}

\section{To cite this version:}

Carine Edith Touré, Christine Michel, Jean-Charles Marty. Refinement of Knowledge Sharing Platforms to Promote Effective Use: A Use Case. 8th IEEE International Workshop on Knowledge Acquisition, Reuse and Evaluation (KARE 2015) in conjunction with 11th International Conference on Signal-Image Technology and Internet- Based Systems (SITIS 2015), Nov 2015, Bangkok, Thailand. pp.680-686, 10.1109/SITIS.2015.127 . hal-01263423v2

\section{HAL Id: hal-01263423 \\ https://hal.science/hal-01263423v2}

Submitted on 15 Mar 2016

HAL is a multi-disciplinary open access archive for the deposit and dissemination of scientific research documents, whether they are published or not. The documents may come from teaching and research institutions in France or abroad, or from public or private research centers.
L'archive ouverte pluridisciplinaire HAL, est destinée au dépôt et à la diffusion de documents scientifiques de niveau recherche, publiés ou non, émanant des établissements d'enseignement et de recherche français ou étrangers, des laboratoires publics ou privés. 


\section{Refinement of Knowledge Sharing Platforms to promote effective use: A use case}

\author{
Carine Edith TOURE, Christine MICHEL \\ University of Lyon, CNRS \\ INSA-Lyon, LIRIS, UMR5205, F-69621 \\ Lyon, France \\ \{carine-edith.toure, christine.michel $\} @$ liris.cnrs.fr
}

\author{
Jean-Charles MARTY \\ University of Lyon, CNRS \\ University of Savoie, LIRIS, UMR5205, F-69622 \\ Chambéry, France \\ jean-charles.marty@liris.cnrs.fr
}

\begin{abstract}
This work focuses on the improvement of a line of corporate knowledge management systems, knowledge repositories. For the implementation of such systems, companies can deploy important means for small gains. Indeed, management services often notice very limited use compared to what they actually expect. We present a use case of a five-step re-designing user-centered approach that combines a top-down content architecture, integration with other corporate information systems and adapted interfaces and interactions design to increase the use of these artifacts. Our implementation is done on the knowledge repository used by operators from Société du Canal de Provence (SCP), a French water management company. Their system was taken into production but very occasionally used. We describe the reasons for this limited use and we propose a design methodology adapted to the context. Promoting the effective use of the system, our approach has been experimented and evaluated with a panel of users working at SCP. Results of our semi-structured questionnaire reveal that more than half of the participant are satisfied and present a positive attitude towards the re-designed system.
\end{abstract}

Keywords- knowledge management methods; knowledge repositories; computer supported collaborative work; humancomputer interactions; user-centered design; information architecture; enterprise social networks

\section{INTRODUCTION}

Knowledge management systems (KMS) are a line of information technologies that focus on creating, gathering, organizing, and disseminating an organization's "knowledge" for managerial and professional workers [1]. Their success depends on their use by knowledge workers. As a matter of fact, it is only by an actual and continuous use that we can observe artifact and information appropriation, technical support, exchanges among participants and change of practices. For various reasons [2], it is common to find that KMS are slightly used and fail within organizations. The causes are of functional order (too complex technology, not meeting the workers' needs, inappropriate formalization of knowledge, etc.), of managerial order (inadequate or non-existent management support), or of social order (inappropriate choice of technology according to the cultural context or work practices). Several major research streams strive to propose solutions for successful knowledge management initiatives within companies. For example, the research area of Management and Information Sciences propose a large panel of models for knowledge management (KM) success. These models are largely normatively and prescriptively oriented but with a lack of technologydesign orientation as well as a micro-scale perspective of knowledge sharing practices [3]. In Computer Science, specifically in the stream of artificial intelligence and knowledge engineering, tools and methods have been proposed to formalize workers' know-how, complex sets of data and procedures, and make them reusable. However, this is done most of a time in a strictly technical manner that lead to very complex systems, far from users' expectations and practices. In [4], the author shows that appropriating knowledge sharing artifacts must be supported by a design and a structuring of contents manipulated but we can observe that very little is done in terms of content organization, integration with other organizational information systems, integration of professional/social practices and interfaces design and interactions.

The objective of our work is, ultimately, to propose a design methodology that produces more usable and adapted systems; that is artifacts with content organization and interfaces matching knowledge workers' needs and professional practices and integrated with other organizational information systems what we believe will minimize the risks of knowledge sharing systems failure. This paper will present a use case in a French hydraulics company Société du Canal de Provence (SCP) where the knowledge has been formalized into a knowledge repository (KR). We focus our proposal on a method for re-designing an existing KR. This approach has been implemented in real context and pre-tested in order to provide elements of evaluation and feedback for further works.

The general research question in this article is how to re-design a KR to make it more usable? More specifically how designing for a better context adapted content organization and artifact integration into professional practices can promote a better acceptation by corporate users? To do this, we propose in this work to use a usercentered design method to understand the corporate organization and find the most appropriated way to combine conventional knowledge design engineering methods with Architecture Information, a method proposed in Human-Computer Interaction (HCI).

The organization of this paper is as follows. In paragraph 2 we present a review of literature. Paragraph 3 describes our re-designing approach. In paragraph 4 , we show how it has been implemented within SCP. We then conduct an a priori assessment of our approach through a semi-structured questionnaire to users. Finally, we conclude and present our further research works. 


\section{REVIEW OF LITERATURE}

\section{A. Overview of Knowledge Engineering methods}

KMS design in Knowledge engineering consists most of the time in formalizing of all procedures and know-how that structure the worker activity. In [5] for example, the KOD method presented attempts to codify the knowledge of an expert from his free speech. The MEREX method [2] developed at Renault, proposes to make returns on operating experience in the form of sheets. The MASK method [5] consists in structuring the knowledge of experts into corpus of documents and information, the dissemination of this knowledge in the company and their integration into company processes is based on a set of models to address and describe the activity knowledge. The process leads to the publication of a structured synthesis of knowledge into a Knowledge Repository (KR). In their final state, these KR are multimedia centers of documentation on knowledge. They allow finding, understanding and using information easily.

Nevertheless, there are in these different methods, low consideration of the end user in the design process, and in the design of access modes and organization of information that may impede the actual exploitation of knowledge.

\section{B. Design methods from Human-Computer Interactions}

\section{1) User-centered design methods}

The HCI vast research area is dedicated to study, plan and design modalities of interaction between the user and the computer. The challenge is not only to produce useful, usable and acceptable interactions but also to improve user experience according to its value system, its context of activity and its objectives. User experience is defined as the set of perceptions of a user when interacting with a product [6]. User-centered design is a philosophy and an approach that takes into account needs, expectations and characteristics of end users at every stage of the design process [7]. Reference [8] proposes job shadowing and contextual interviews as approaches to better understand users' expectations. They consist for the designer to accompany and observe the worker during his activity for a certain period of time (job shadowing) or interview the worker about his core business activities. Focus groups are another mean to understand users' professional context and collect their needs. Reference [9] shows that focus group can be a powerful tool for artifact refinement and proposes a detailed description of how to conduct them.

2) User-centered design methods in Knowledge Management

A couple of researchers applied other user-centered design tool for designing KMS [10][11]. They generally use a 3 steps methodology based on models: user model (identification of end-users and their relationships), tasks model (identification of general features of the system) and content model (content and organization of the user interface). These works have been successful in developing usable knowledge sharing artifacts, but have not yet been proven in the field of collaborative sharing and seeking of knowledge. Paper [12] presents the designing process of a web-tool for collaborative knowledge sharing within medical communities using focus groups. His paper focuses on the description of user needs and their transcription but give less information about the other stages of the design process.

Because our paper aims to describe a complete step-bystep approach integrating, among other features, content organization, we need, on the sidelines of the user needs gatherings, to define information structure, interactions and access modes to the artifact.

\section{3) Information Architecture}

The stream of Information Architecture's aim is the presentation of information in the most appropriate way, according to end-users and their use context. A good information architecture has to be browsable (the user is not confused), coherent (semiotic adapted to the context of use), adaptable, simple (sufficient amount of presented information), able to make recommendations for information consultation [13]. Paper [6] proposes a general conceptual framework to structure the design, particularly suited for Web applications. This concrete and detailed approach is based on five stages: strategy, scope, structure, skeleton and surface. These steps describe how to pass abstract elements of the product design to the most concrete elements. To structure the information, the author suggests using either a top-down approach (from the needs and objectives of the system to organize information) or a bottom-up approach (use categories and sub categories that spontaneously emerge from designer's analyses of information). In our case, the top-down approach seems to be the most adapted because the artifact organization and contents manipulated must match the organizational structure of the enterprise and the user's schemes of professional activity.

\section{Summary}

Conventional knowledge management methods are incomplete because they often lead to KMS that are far from user expectations. Participatory design techniques and structuring of information offer ways for designers to better understand expectations of end users. In the next paragraph, we describe the methodology used.

\section{A FIVE STEPS APPROACH}

Companies are already sensitized to the interest of formalizing business knowledge and build KMS. Most of them have already invested in these strategies but could not get a really usable system or accepted by those in the field. That is why we propose a re-design approach based on an existing knowledge capitalization. We use as a basis for our approach the 5 elements of the conceptual framework of [6] which is adapted to web platforms and pretty much easy to apply in real context. The phases are composed of different methods from the literature that was adapted to and implemented in our context. The steps may overlap if necessary. The process is iterative. An evaluation of the resulting prototype is done and may lead to a redefinition of previous choices.

\section{A. Need analysis}

In this step, we propose to analyze the initial situation of the KMS, the users' needs, his professional practices and the system objectives. This information gathering allows us to work on capitalized knowledge, the business context and the expectations of the users and of the company. The objective is to observe difficulties the users 
may encounter in front of the existing KMS and find appropriate solutions. For a knowledge book, it is interesting to observe users' reaction in front models of organization, media or forms of navigation. Concerning the other aspects, an immersion in the industrial environment is required; matching methods and contextual interviews are appropriate means to understand the environment of use and the needs [8]. In addition, mindmapping exercises [2] used during focus groups can help to better understand the business vocabulary through games characterization. Mind mapping methods are ludic ways to classify the important business concepts into categories and super categories that will help us to understand workers' activity and the information structuring.

\section{B. Definition of the new KMS}

This step is used to define the features of the artifact that meet the needs. Nowadays, new technologies of information and knowledge (Social Networks, Blogs, Wikis, etc.) are becoming increasingly present in daily people habits. Hence, companies and workers are increasingly interested in easy sharing and exchanging of information via Enterprise Social Networks (ESN) [15] and are turning out to these new forms of exchange and communication [14]. They look for ways to exploit them. Paper [15] justifies the effectiveness of ESN in knowledge management by carrying out an analysis based on the knowledge creation model of Nonaka [16]. This is why we assume that discussing with users about refining the KR into an ESN may be a valuable choice. This assumption will be evaluated in future works to see if such a solution could be better than another collaborative way of sharing knowledge.

Hence, designers will discuss during focus group the usefulness and the format of common features within ESN which are members' directory, blogs, news, statistics, newsletter, photo album, dialogue groups, events, polls, discussion forums. User roles and social features are essential in ESN. The definition of roles will also be discussed with users. Most of the time, collaborative blogs within ESN propose a repartition of roles as follows: a redactor, a commentator, a validator and a general manager.

\section{Design of the information structure}

This step addresses the specification of interaction formats adapted to the features and information architecture of the system. This phase is closely related to the results of the analysis in the first step. It consists in designing patterns of interaction and structuring information models that are familiar to users. If the forms of interaction in the ESN are already pervasive in users' habits, we recommend keeping them. Structuring the content on the other hand, should be investigated. Among the two approaches proposed by [6] and presented above, we propose to implement the top-down approach. Content will be structured according to the corporate organization (departments, services, teams, projects, etc.) workers are familiar with. Mind mapping sessions conducted during focus groups will help identify key concepts as well as their different facet and forms of information; they will then be classified within the defined organization. Access modes to and from other information systems will also have to be studied and integrated into the knowledge sharing artifact so that users can keep a link with of other corporate artifacts they currently use.

\section{Design of the skeleton}

This step is used to design the main functional areas and how they are interconnected. The use of the personas methodology [17] may be helpful at this stage. Personas are virtual characters that correspond to the end users, they allow designers to really get into the skin of end users and make proposals that best fit them. They are important to specify the navigation schema connecting the different functionalities.

\section{E. Visual Design}

The general graphical appearance and textual fonts will be determined in this phase. We recommend setting the visual design in accordance with the Charter of communication and graphical design of the company to maintain familiarities with interfaces. Moreover, improvements in usability can be made if necessary. One possibility is to stage the main use cases, and discuss with the users on proposed models. We therefore recommend a prototyping approach which allows the improvement of the visual design.

The last two steps of our methodology, Design of the Skeleton and Visual Design, are highly sensory and will impact the user experience. The designer will have to be particularly careful when developing the platform in terms of ergonomics; He will also be able to develop motivators, all in accordance with user's expectations. This may require browse regularly through these steps.

\section{IMPLEMENTATION}

Société du Canal de Provence is a company in the south of France, specialized in services related to the treatment and distribution of water for companies, farmers and communities. It employs a significant number of collaborators called Operators. They are responsible for maintenance of hydraulic infrastructures (canals, pumping stations, water purification stations, etc.). Their intervention territory is divided into ten geographic areas called Operating Centers (OC). The water infrastructures that composed the different OC are complex, various and require to be maintained in ways corresponding to the geographical area. The administrative contact and maintenance procedures are also specific to each infrastructure. Any error on one of them infers consequences for the entire downstream hydraulic network. To help them in their daily work, they often use a geographic information system (NetView) and an event management system (Supervision) for distant monitoring of incidents that may occur on hydraulic infrastructure. The operators have a knowledge intense work that is particularly difficult. SCP in 1996, invested in a KR named ALEX (Aide à L'EXploitation). ALEX makes its information accessible through return on experience sheets in HTML format located within a directory on a dedicated server in each OC. SCP however found that it was little used despite the fact that there is, among collaborators, a real awareness of the usefulness of such a system. A preliminary study allowed us to identify problems at the level of ergonomics and at the level of access processes 
and information update (experience sheets was very long to create since they have to write them first in a .doc format and then turn it into HTML format, only a few workers had the time and the technical capabilities to execute the process). This context is particularly representative of design issues that can reveal KMS. We applied our methodology to redesign their system. The redesign was carried out with a working group of twelve employees, representing in terms of position and skills of all the users. It took six months and six working meetings to deliver a first prototype to users.

\section{A. Deployment of the methodology}

1) Need analysis: The study of the initial system showed that the information filled in on business procedures was generally of good quality, which is fine since we haven't had to rework on the formalization of the knowledge itself. Users' needs collected during focus group can be summarize as follows: workers wish to have an accessible platform from both the office and the outside (web platfom), that is easy to learn but effective (casual and responsive functionnalities), which reduces the time for entering information (content easily updatable), facilitates data search (a good search engine) and allows exchanges between employees (with a social area). Our proposition of implement an ESN therefore was well accepted since it met the needs.

2) Specification of the ESN: During focus groups, the following roles have been defined: the administrator, the validator, the contributor and the commentator. Employees, depending on the role they have in the system, are more or less involved in the animation of the platform and content validation. These roles helped develop access features for system security levels and promote empowerment of actors. The features discussed and chosen to be integrated in the ESN are the submission, moderation and publication of pre-formatted forms based on roles, possibility for users to submit comments on the experience sheets, pictures of new activity performed in each operating center, photo galleries, links from and to other corporate information systems (NetView, Supervision). The architecture of the new system is proposed on Fig. 1. The submission of experience sheet is made by the contributor under

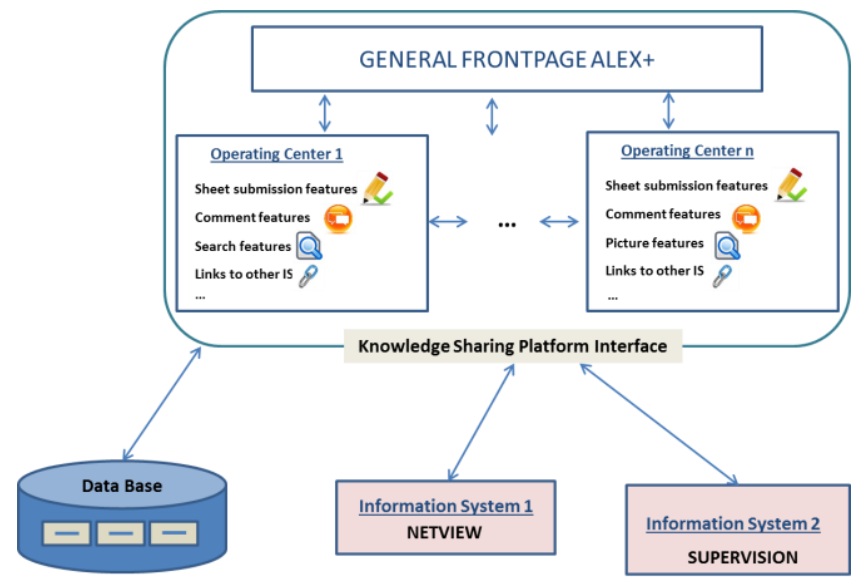

Figure 1. View of ALEX+ architecture. The plaform is organized according to the different operating centers. Integration with other information systems NetView and Supervision is done by the mean of links. moderation of the validator or the administrator. It is done using forms with large areas of open writing because the activity is too complex to be defined by a structure; employees without any role distinction communicate by commentaries left on the sheets. These comments serve to convey the appreciation of the reader regarding the record, as its content is a good idea to generalize or if there is a need for additional information; research content is natural language or keywords; photos of the galleries will be indexed according to the operating structures and equipment in order to facilitate research.

3) Design of the information structure: We organized the ESN according to the organization of OC in SCP. Each OC is represented as 'Collection' containing several hydraulic infrastructures. Each infractructure contains one or several equipments on which several operations can be executed. These operations done by the collaborators on infrastructures are described in experience sheets, with descriptions of equipment, operating instructions, processes and alarms. This resulted in the definition of eleven types of sheets: presentation, equipment, set operating instructions, hydraulic diagram, spreadsheet, process, operation, alarm, contract / contact and detail. Each item is described by a presentation sheet that can be associated with one or more sheets of the other types. Each sheet is presented as a form formatted according to its type-specific metadata (type of equipment for equipment sheets or instruction name for operating instruction sheets), by cons, the content of fields is open written as shown on Fig. 2.

4) Skeleton Design: This phase was animated by discussions on the basis of a proposal of a skeleton made with a content management system (CMS) named Drupal. The use of a CMS allowed us to accelerate the development and modifications of the prototype according to the users' feedback. In the light of the opinions that have been collected, we made the proposal to reorganize the new system in different functional areas gathering the main features of ALEX that are information, submission, navigation and communication. The content is classified in accordance with the operating centers. Each OC has a dedicated subsite in which each page contains the 5 functional areas described previously. Experience sheets are classified and indexed in accordance with their type.

5) Visual Design: On the visual aspects of the site, we started with a proposal of "theming" and, according to

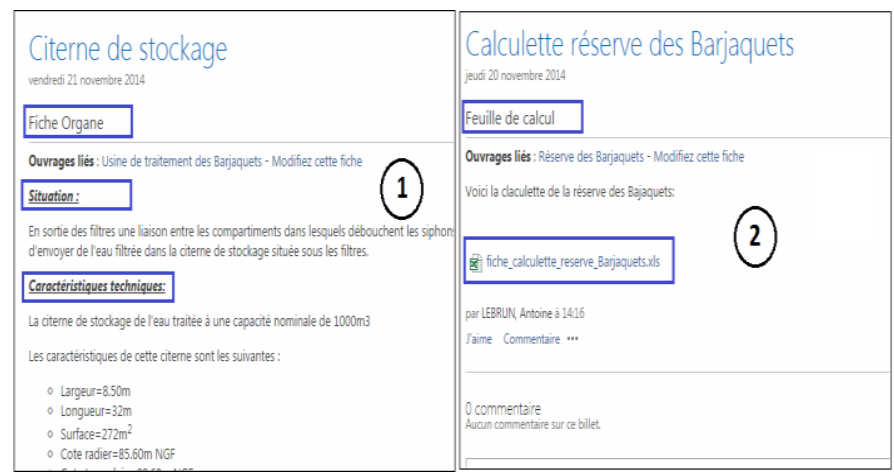

Figure 2. View of two types of sheets. Form 1 is an equipment sheet and form 2 a worksheet. Organization of the content depends on the type: equipement sheets are arranged in predefined paragraphs while a worksheet contains an attached file with a free content textbox. 


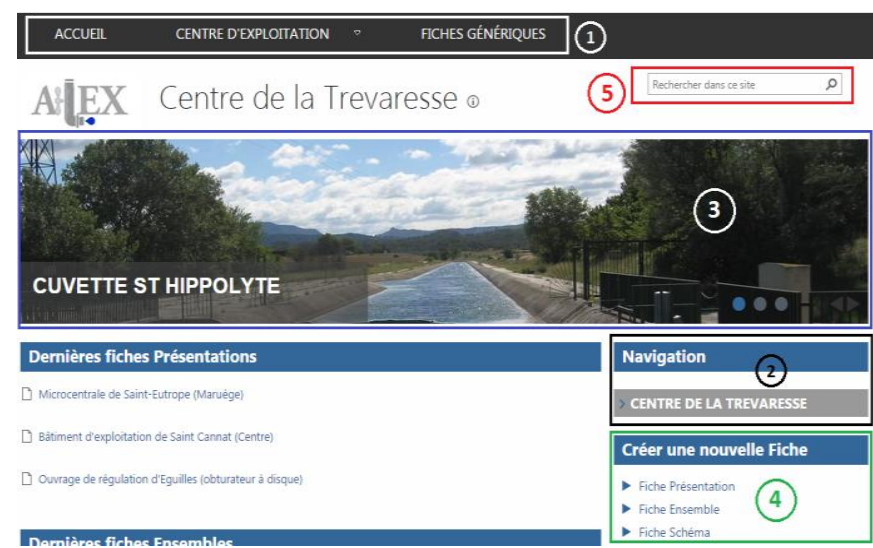

Figure 3. View of ALEX+ Trevaresse OC front page. Boxes 1 et 2 show different type of browsing: with tabs on the top or with a menu on the side. Box 3 present a slideshow of pictures posted in the OC library. In box 4 , we placed the submission options. Box 5 shows the research form

different users' feedback, we adapted the different choices. In this phase, we had to get into the skin of each user type and depending on the use case, to make choices that facilitate the use of the tool. As examples, we can cite the search area that has been enlarged and positioned prominently at the top right corner, the default font for the fill of sheets that has been standardized to Arial, size 12, or the area for data entry that has been enlarged.

6) ALEX+: At the end of the previous works, we delivered a new version of ALEX named ALEX+. We present you the front page of an OC on Fig. 2. Features have been proposed in order to improve the user experience in terms of complexity and duration, during the activity of corporate knowledge. An assessment has been made and is detailed in the next section.

\section{B. Evaluation}

The objective of this assessment was to see if we had managed to transcribe the latent needs of SCP operators and developed an acceptable system. Indeed, quality of a system can be measured by its usefulness (does the system meet the user's needs?) and its usability (is the system functional according to the use context?) [18].

1) Evaluation criteria: Models of technology acceptance divide the acceptance process into two stages. Before the first use, the user built beliefs based on his perceptions of the system. These beliefs leverage his attitude and use intention. The actual acceptance occurs while using the system and infers an appropriation or a rejection. Initial acceptance, first condition for technology success was widely studied in literature. As major models, we can cite TAM [19] or UTAUT [20]. The first one considers perceived usefulness and perceived ease of use

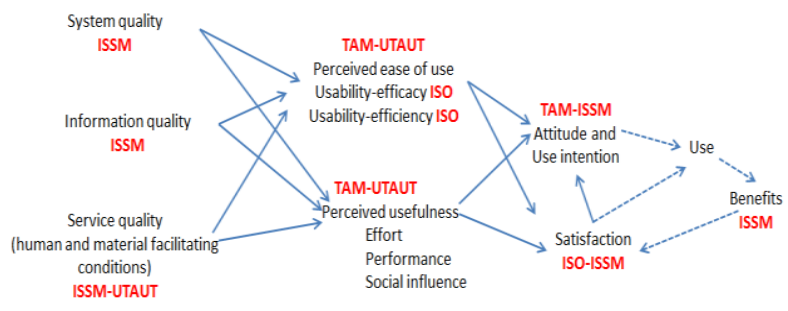

Figure 4. Process for acceptance of technologies avec basic elements for attitudes and users' behaviors. The second one refines the criteria by considering users social characteristics. The ISSM [21] opens up the criteria and considers quality of the system, of the information and of the service as determinants of positive intention and use. The ISO 9241-11 model considers usability (efficacy, efficiency and satisfaction) as a required condition of use [18]. Efficacy and efficiency are first perceived and infer in the construction of satisfaction and positive attitude towards the technology. During the use of the technology, these opinions consolidate or evolve according to the perceived benefits; they condition long-term use with other determinants like Use Context. The whole acceptance process is represented on Fig. 4.

A successful deployment of ALEX+ in real context is related to a positive first acceptance that is why we focused on measuring these criteria first. Measurement of actual benefits and satisfaction being long to construct, we were not able to assess them in this study. Usage analysis depends in addition on many other organizational factors. The quality of our methodology was therefore assessed on the basis of an a-priori acceptance.

2) Data gathering: The evaluation was conducted with the members of the working group. This was about completing a semi-structured questionnaire organized into nine sections describing the nine factors listed in the previous model: System Quality (QS), Quality of information (QI), perceived Ease of use (FUP), Attitude toward the use of the application (ATT), Intention to use (IC), Service Quality (How is the system proposed by the SCP?), professional perceived Usefulness related to the use of the application (UPR), Personal perceived Usefulness related to the use of the application (UPE) and Satisfaction (SA). Each section contains a series of 4 to 6 questions [22]. For each section, we left blank textboxes so that participants can express themselves on open questions.

TABLE I. RESULTS SUMMARY

\begin{tabular}{|l|l|l|l|l|l|l|l|l|}
\hline & \multicolumn{2}{|}{ QS and QI } & \multicolumn{2}{|c|}{ UP } & \multirow{2}{*}{ FUP } & \multicolumn{2}{c|}{ ATT and IC } & \multirow{2}{*}{ SA } \\
\cline { 1 - 1 } & QS & QI & UPR & UPE & & ATT & IC & \\
\hline PA(\%) & 96,3 & 83,3 & 64,4 & 66,7 & 88,9 & 85,2 & 71,1 & 86,1 \\
\hline $\mathrm{NA}(\%)$ & 0 & 2,8 & 26,7 & 22,2 & 0 & 0 & 17,8 & 0 \\
\hline $\mathrm{A}(\%)$ & 3,7 & 13,9 & 8,9 & 11,1 & 11,1 & 14,8 & 11,1 & 13,9 \\
\hline
\end{tabular}

3) Results: The analysis of the results reveal a majority of positive answers to questions about Quality of System, of Information and Satisfaction. About Perceived Ease of Use, more than half of the participants wrote in substance that "Alex+ should be simpler to use than its previous version but we could judge it actually with further use". Concerning the attitude towards system criteria, one of the participants pointed out that "he thinks he could use the system by now without major problems but this feeling could change with time". Generally, almost all the feedbacks are positive regarding user satisfaction. However, the comments left by the users about long-term use point out the limits of this assessment 
that just consider the a-priori acceptance. The risk that users may lose motivation to use the system on a long term usage is present. First acceptance does not guaranty continuous and sustainable use [22].

\section{CONCLUSION AND DISCUSSIONS}

Given the limits of conventional knowledge management methods that focus specifically on knowledge formalization at the expense of the final interface, we proposed a concrete user-centered redesigning approach that turns knowledge repositories into enterprise social networks. Our approach combines methods from knowledge engineering and information architecture. We implemented our approach in SCP and as a result we obtained a prototype, ALEX +. ALEX + was evaluated by a panel of users. It shows that collaborators are generally satisfied with the proposals that were made in the final system and will tend more to use it. We can however identify a couple of limitations in our approach. Firstly, the limited number of participants in the workgroup allows us to only have the viewpoints of a small part of the actual user population; an assessment of a larger amount of people in SCP and also in other companies would help us have a better insight of the impact of our methodology on the KMS use in the company. Secondly, an ideal experimental approach would be to do a comparative evaluation of our methodology with others proposed by literature in the domain of design of corporate KMS. More generally, with our approach, we can just have an overview of the users' intentions but not of the effective use. The choice of ESN as a solution for more usable knowledge management artifacts also need to be investigated to evaluate if such a solution is generally better than another one.

These points are planned for future work. Indeed, KMS are really effective when users appropriate it, consult the available information, discuss, comment and update contents. This is what we call sustainable knowledge management. To achieve this, we need to add other features in the system. We believe that metacognitive assistance features like indicators of awareness may be useful [23]. Indeed, by proposing activity indicators, we can promote a reflexive dynamic of learning by user selfregulation processes [24]. For example, users by visualizing the impact of their contribution on other actors in the company may be more motivated to use the system. Conversely, by identifying the comments that were made on experience sheets related to their professional field, they may become aware of new procedures or changes in business practices and thus increase the credit given to the developed tool. As such, comments could be seen as a recommendation to consult. On the sidelines of this work, we plan to monitor the activity and assess these new features by analyzing traces of activity [25]. These traces provide much more diagnostic of use by sector and functionality. What we are doing now is therefore to identify, still with an incremental approach, which indicators and interaction modalities may be most suitable. Phases 4 and 5 of our method are mainly concerned; the design that affects the sensory and user experiences.

\section{ACKNOWLEDGMENT}

This research work is initiated by the Operation Service within the Technique and Water Direction of SCP. We would like to thank, Jean-Luc DELTOUR and Frederic ROMITTI, who are responsible for the ALEX project at SCP, and all the collaborators who participate to the project.

\section{REFERENCES}

[1] M. Alavi and D. E. Leidner, "Knowledge management systems: Issues, Challenges, and benefits," vol. 1, no. February, pp. 1-37, 1999.

[2] J. Y. Prax, Le Manuel du Knowledge Management Une approche de 2ème génération, Dunod. France, 2003.

[3] M. S. Ackerman, J. Dachtera, V. Pipek, and V. Wulf, "Sharing Knowledge and Expertise: The CSCW View of Knowledge Management," Comput. Support. Coop. Work, vol. 22, no. 4-6, pp. 531-573, Aug. 2013.

[4] V. Folcher, "Appropriating artifacts as instruments: when design-for-use meets design-in-use," Interact. Comput., vol. 15 , no. 5, pp. 647-663, 2003

[5] J. L. Ermine, Management et ingénierie des connaissances - Modèles et méthodes, Hermès-Lav. France, 2008.

[6] J. J. Garrett, The elements of user experience Centered Design for the Web and Beyond, 2nd Edition, New Riders. Berkeley, 2011.

[7] J. Nielsen, Usability Engineering, Academic P. USA 1993.

[8] L. Mathis, Designed for Use - Create Usable Interfaces forApplications and the Web, Pragmatic . USA, 2011.

[9] M. C. Tremblay and A. R. Hevner, "Focus Groups for Artifact Refinement and Evaluation in Design Research," Commun. Assoc. Inf. Syst., vol. 26, 2010.

[10] H. Karner and G. Droschl, "Usage-Centered Interface Design for Knowledge Management Software," J. Univers. Comput. Sci., vol. 8, pp. 634-643, 2002.

[11] S. Rinkus, M. Walji, K. A. Johnson-Throop, J. T. Malin, J. P. Turley, J. W. Smith, and J. Zhang, "Human-centered design of a distributed knowledge management system," $J$. Biomed. Inform., vol. 38, pp. 4-17, 2005.

[12] F. Cabitza, "On a QUESt for a web-based tool promoting knowledge- sharing in medical communities," Behav. Inf. Technol., no. October, pp. 37-41, 2014.

[13] A. Resmini and L. Rosati, Pervasive Information Architecture - Designing Cross-Channel User Experiences, Morgan Kau. USA, 2011. 
[14] A. Dudezert and I. Boughzala, Vers le KM 2.0: Quel management des connaissances imaginer pour faire face aux défis futurs?, Vuibert. Paris, 2008.

[15] R. Zammit and M. Woodman, "Social Networks for Knowledge Management," in The Third International Conference on Social Eco-Informatics, 2013.

[16] I. Nonaka, "A dynamic Theory of Organizational Knowledge Creation," Organ. Sci., vol. 5, no. 1, pp. 14-37, 1994.

[17] A. Boucher, Ergonomie Web - Pour des sites web efficaces, Eyrolles. France, 2007.

[18] F. Février, "Vers un modèle intégrateur 'ExpérienceAcceptation': Rôle des affects et de caractéristiques personnelles et contextuelles dans la détermination des intentions d'usage d'un environnement numérique de travail," Université de Rennes 2, 2011.

[19] F. D. Davis, "User acceptance of information technology: system characteristics, user perceptions and behavioral impacts," Int. J. Man-Machine Stud., vol. 38, pp. 475-487, 1993.
[20] V. Venkatesh, M. G. Morris, M. Hall, G. B. Davis, F. D. Davis, and S. M. Walton, "User acceptance of information technology: Toward a unified view," $M I S Q$., vol. 27, no. 3, pp 425-478, 2003.

[21] W. H. Delone, "The DeLone and McLean model of information systems success: a ten-year update," J. Manag. Inf. Syst., vol. 19, no. 4, pp. 9-30, 2003.

[22] C. E. Touré, "Mise en place d'un dispositif de gestion des connaissances pour le soutien à l'activité industrielle," INSA Lyon, Master recherche, 2013.

[23] J.-C. Marty and T. Carron, "Observation of Collaborative Activities in a Game-Based Learning Platform," IEEE Trans. Learn. Technol., vol. 4, no. 1, pp. 98-110, Jan. 2011.

[24] S. George, C. Michel, and M. Ollagnier-Beldame, "Usages réflexifs des traces dans les environnements informatiques pour l'apprentissage humain," Intellectica, vol. 1, no. 59, pp. 205-241, Jun. 2013.

[25] M.-H. Karray, B. Chebel-Morello, and N. Zerhouni, "PETRA: Process Evolution using a TRAce-based system on a maintenance platform," Knowledge-Based Syst., Mar. 2014. 